\title{
Case report of Plasmodium ovale curtisi malaria in Sri Lanka: relevance for the maintenance of elimination status
}

\author{
Sharmini Gunawardena ${ }^{1 \dagger}$, Rachel F. Daniels ${ }^{2,3 \dagger}$, Thishan C. Yahathugoda ${ }^{4 \dagger}$, Mirani V. Weerasooriya ${ }^{4}$,
} Katelyn Durfee ${ }^{2}$, Sarah K. Volkmann $2,3,5$, Dyann F. Wirth ${ }^{2,3}$ and Nadira D. Karunaweera ${ }^{1^{*}}$ (D)

\begin{abstract}
Background: Following its recent certification as malaria-free, imported infections now pose the greatest threat for maintaining this status in Sri Lanka. Imported infections may also introduce species that are uncommon or not previously endemic to these areas. We highlight in this case report the increasing importance of less common malaria species such as Plasmodium ovale in elimination settings and discuss its relevance for the risk of malaria resurgence in the country.

Case presentation: A 41-year-old patient from southern Sri Lanka was diagnosed with malaria after 8 days of fever. Microscopy of blood smears revealed parasites morphologically similar to $P$. vivax and the rapid diagnostic test was indicative of non-P. falciparum malaria. He was treated with chloroquine over 3 days and primaquine for 14 days. He was negative for malaria at a one-year follow-up. Molecular testing performed subsequently confirmed that infection was caused by $P$. ovale curtisi. The patient gave a history of $P$. vivax malaria treated with chloroquine and primaquine. He also provided a history of travel to malaria endemic regions, including residing in Liberia from May 2012 to November 2013, throughout which he was on weekly malaria prophylaxis with mefloquine. He had also visited India on an eight-day Buddhist pilgrimage tour in September 2014 without malaria prophylaxis.

Conclusions: It is crucial that every case of malaria is investigated thoroughly and necessary measures taken to prevent re-introduction of malaria. Accurate molecular diagnostic techniques need to be established in Sri Lanka for the screening and diagnosis of all species of human malaria infections, especially those that may occur with low parasitemia and are likely to be undetected using the standard techniques currently in use. In addition, ascertaining whether an infection occurred through local transmission or by importation is critical in the implementation of an effective plan of action in the country. This new era emphasizes the global nature of regional malaria elimination. Increasing global surveillance and tool development are necessary in order to "fingerprint" parasites and identify their origin.
\end{abstract}

Keywords: Plasmodium ovale curtisi, Elimination program, Malaria, Sri Lanka

\section{Background}

Sri Lanka was recently certified as a nation free of malaria by the World Health Organization (WHO), having recorded its last indigenous case in October 2012 [1]. High vigilance has been maintained, with all reported cases of malaria being investigated either microscopically

\footnotetext{
* Correspondence: nadira@parasit.cmb.ac.lk

${ }^{\dagger}$ Equal contributors

'Department of Parasitology, Faculty of Medicine, University of Colombo, 25, Kynsey Road, Colombo 8, Sri Lanka

Full list of author information is available at the end of the article
}

or by rapid diagnostic tests (RDT), with radical treatment and follow-up provided. Imported cases have posed the greatest threat for sustaining malaria elimination [2-4].

An indigenous case of $P$. ovale was reported from Sri Lanka in 2008 [5]. The patient had given a history of repeated attacks of $P$. vivax malaria, the last of which had occurred only two weeks prior to the episode of admission. Microscopy had revealed asexual stages resembling those of $P$. vivax and blood was sampled for the analysis of molecular markers of drug resistance. 
He had been treated as a case of treatment failure until molecular testing confirmed it as a $P$. ovale infection. This was considered an indigenous infection as the patient neither gave a history of travel overseas nor received any transfusion of blood or blood products [5].

Here we report another case of malaria due to $P$. ovale in Sri Lanka. Ascertaining whether this infection occurred through local transmission or by importation is critical in the implementation of an effective plan of action for malaria surveillance in Sri Lanka. The relevance of this case for the risk of malaria resurgence in the country is discussed.

\section{Case presentation}

A 41-year-old police officer from Wanduramba, Galle (Southern Province, Sri Lanka) presented to the Teaching Hospital in Karapitiya on May 12, 2015, with fever, chills, and rigors that had persisted for three days. On examination, the patient was febrile but had no respiratory, gastro-intestinal, or circulatory abnormalities and no clinical evidence of any enlargement of the spleen or the liver. He had developed a fever while attending a residential meditation program at a center situated in Pinnawala, Rambukkana (Kegalle district, Sabaragamuwa Province), where he had been residing since the beginning of April 2015.

He was positive for dengue antibodies and had a low platelet count $(\sim 77,000 / \mu \mathrm{L}$; normal range: $150,000-$ $400,000)$; based on these criteria, he was treated for dengue fever. Since the fever did not subside after eight days, the patient was referred to the Department of Parasitology at the Faculty of Medicine of the University of Ruhuna in order to exclude malaria. Microscopy of blood smears revealed parasites morphologically similar to $P$. vivax (Fig. 1), with a parasite count of $7695 / \mu \mathrm{L}$ and rapid diagnostic test (RDT, CareStart Malaria HRP2/pLDH Combo, Access Bio, Inc. USA) findings indicative of nonP. falciparum malaria. The patient was managed as a case of $P$. vivax malaria. He recovered completely following treatment with 25 milligram (mg) of chloroquine base per kilogram (kg) body weight (bw) administered over three days $(10 \mathrm{mg}, 10 \mathrm{mg}$, and $5 \mathrm{mg}$ base per $\mathrm{kg}$ bw on days 1 , 2 , and 3 respectively) and was discharged with a 14-day course of primaquine at a daily dosage of $0.25 \mathrm{mg} / \mathrm{kg}$ bw to achieve a radical cure [6]. He was followed up by the Anti-Malaria Campaign (Ministry of Health, Sri Lanka) with weekly samples of blood tested for the presence of malaria antigens as well as smears evaluated for parasites during the initial 28 days after discharge, and continued monthly thereafter up to one year, with all antigen and blood smears negative for malaria.

Molecular testing was performed to confirm the diagnosis. However, it was not done for confirmation of parasite clearance at the end of follow up. Parasite DNA was extracted from a sample of venous blood collected prior to the commencement of treatment using a QIAamp DNA Blood Mini Kit (Qiagen GmbH, Hilden, Germany). To identify the species of Plasmodium present in the sample,

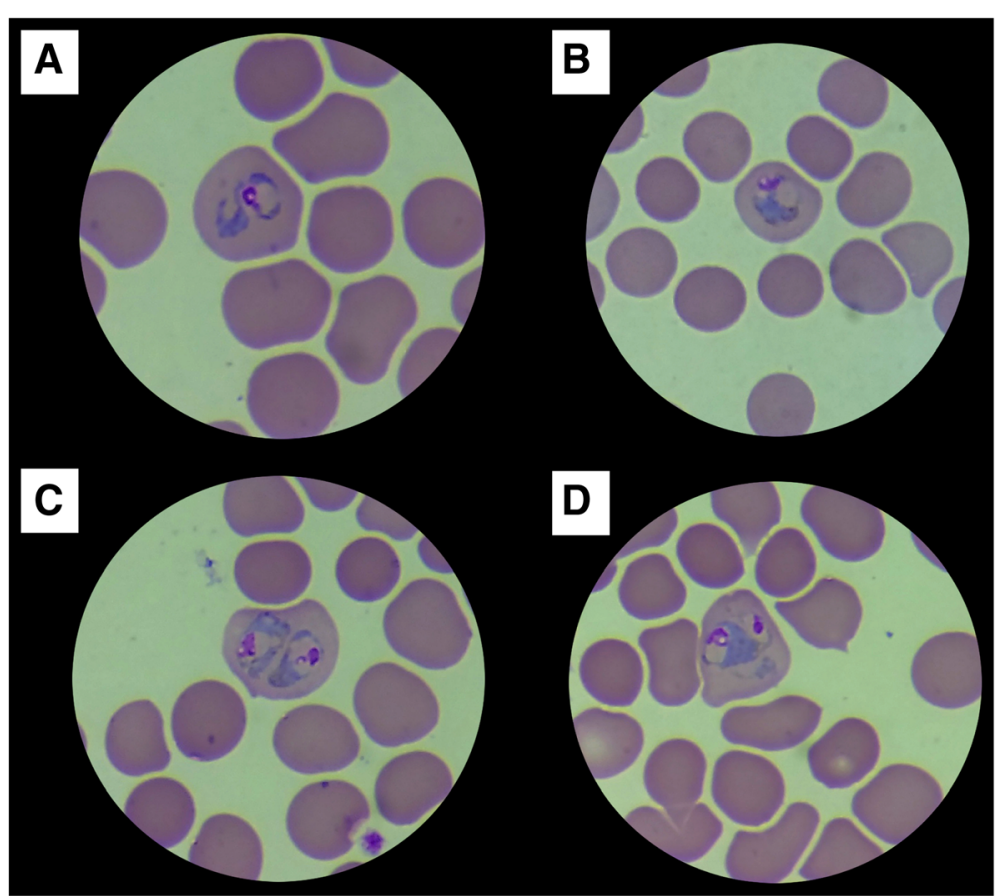

Fig. 1 Giemsa stained thin blood smears (10 × 100 magnification). a-d Trophozoites of Plasmodium ovaleNote the enlarged parasitized red cells (a-d) and the presence of multiple parasites within red cells $(\mathbf{c}, \mathbf{d})$. 
the extracted DNA was first amplified by nested polymerase chain reaction (PCR) using the UNR and PLF and NewRevshort and NewPLFshort primers as previously described [7]. The nested PCR products were visualized by agarose gel electrophoresis and the bands compared to $P$. falciparum, $P$. ovale, and $P$. malariae positive controls from Senegal [8] as well as to a no-template water negative control. The positive colonies were cloned using a commercial kit (CloneJET PCR Cloning Kit, Thermo Scientific) following manufacturer directions and sent for Sanger sequencing (Macrogen Corp., Rockville, MD USA). A BLAST search of the NCBI database revealed that, contrary to the clinical suspicion, the patient sample was positive not for $P$. vivax, but for $P$. ovale curtisi, with a $99 \%$ identity to previously reported sequences. The patient sample sequence has been deposited to GenBank as accession number KY111277.

To assess the possible sources of this malaria infection, a detailed history was taken (Fig. 2). The patient had a history of malaria contracted in 2000, while he was working in Habarana (Anuradhapura district, North Central Province). According to the information provided, his episode of $P$. vivax malaria was treated with three days of chloroquine and 14 days of primaquine. He also provided a history of travel to malaria endemic regions, including residing in Liberia from May 2012 to November 2013 as part of a United Nations peacekeeping mission. Throughout his stay in Liberia he was on weekly malaria prophylaxis with mefloquine. Upon returning to Sri Lanka, he was posted to Kuchchaveli, Trincomalee (Eastern Province, Sri Lanka), where he remained for two months. Thereafter, he had been living at home in Waduramba, Galle. His travel history also indicated he had visited India on an eight-day Buddhist pilgrimage tour in September 2014, when he stayed in Bodh Gaya, Uttar-Pradesh and Nepal during this visit. Malaria prophylaxis was not used during this tour.

From November 2014 to March 2015, he had been at a residential meditation center in Siripagama, Kuruwita (Ratnapura district, Sabaragamuwa Province). Thereafter, he had briefly visited his home in Galle. In early April 2015 he had gone to the meditation center in Pinnawala, Rambukkana, where he developed the current illness (Fig. 2).

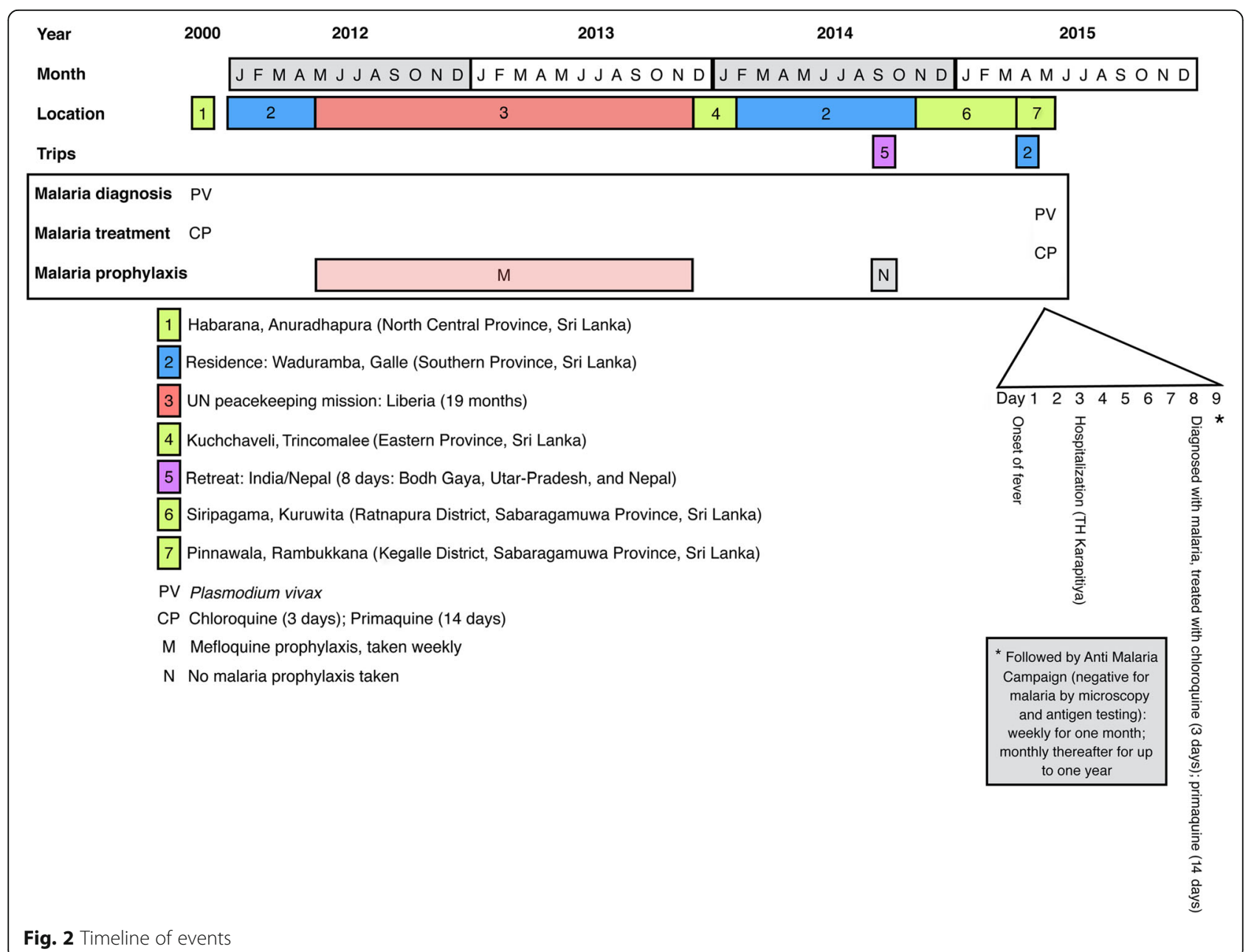


The districts of Kegalle and Ratnapura, where the two meditation centers are located, are low endemic areas for malaria [1]. The meditation center in Siripagama is a popular retreat isolated from human habitation and surrounded by natural jungle, while the center at Pinnawala is more urbanized. At the time the patient was residing at these meditation centers, he had not encountered any foreign residents from whom the infection could have been transmitted.

\section{Discussion and Conclusions}

In the context of the recent WHO certification of Sri Lanka as malaria-free [9], this case report is of particular interest, as it is a parable for the success and risks for countries nearing and maintaining malaria elimination status. Increased international travel correspondingly increases the risk of parasite transmission between and among malaria endemic and non-endemic nations, making the traditional paradigm of a geographically defensible country for malaria elimination no longer feasible. In countries with low transmission or that are maintaining their malaria-free status such as Sri Lanka, imported cases are of concern $[10,11]$. These imported infections may introduce species that are uncommon or not previously endemic to these areas, and detection and diagnosis may be difficult due to declining microscopist accuracy due to lack of practice. P. falciparum and P. vivax are the most commonly reported species in Sri Lanka; thus, even trained microscopists may be challenged to accurately identify other Plasmodium species.

$P$. ovale is one of five species that cause human malaria infection, and is now known to be endemic across tropical regions in Africa and Asia [12-17]. Recent molecular studies indicate that $P$. ovale malaria is caused by two closely related species namely $P$. ovale curtisi and $P$. ovale wallikeri $[18,19]$. Diagnosis of $P$. ovale malaria can be difficult because of low parasitemia levels, mixed infections with other Plasmodium species, and false negative results from malaria RDTs [20]. The developmental cycle of $P$. ovale is very similar to that of $P$. vivax, including changes produced in the infected erythrocytes, and giving cause to tertian fever as well as generating relapses from latent parasites in the liver [13]. While $P$. ovale has traditionally been considered to cause benign clinical disease, several cases with severe complications have been reported [21, 22]. The reported relapse interval after treatment of a primary attack for $P$. ovale ranges from 17 to 255 days [13]. However, delayed primary attacks with $P$. ovale have been observed even after 4 years $[23,24]$.

The similarity of $P$. ovale parasites to $P$. vivax microscopically in blood smears as well as in its clinical course and response to treatment could easily lead to misdiagnosis based on microscopy or RDTs. In this instance, the presence of multiple parasites within red cells as seen in the blood smears led to further investigation based on molecular techniques which helped to differentiate between $P$. ovale and $P$. vivax and further define the infection as $P$. ovale curtisi. Globally, molecular testing in Africa and other Asian settings has revealed a higher incidence of these infections than has been previously reported, and the increasing importance of $P$. ovale and $P$. malariae in a malaria elimination setting in China was recently highlighted [25-27].

Furthermore, the potential introduction of new or uncommon species increases concerns regarding the vector population. The natural vectors of $P$. ovale in Africa are believed to be Anopheles gambiae and A. funestus, while a few other species, namely $A$. albimanus, $A$. quadrimaculatus, A. freeborni, A. maculatus, A. subpictus, A. stephensi and $A$. dirus, have the potential for transmission [13]. Anopheles culicifacies is the major vector of malaria transmission in Sri Lanka, while A. subpictus is a secondary vector [1]. The ability of $A$. culicifacies to transmit $P$. ovale is not known. However, $A$. subpictus as well as $A$. maculatus, which are considered potential vectors of $P$. ovale, are endemic in Sri Lanka [28, 29]. Thus, early detection and treatment of all imported cases becomes imperative in the presence of mosquito vectors and other environmental factors that remain conducive for infection transmission.

At this juncture, it is crucial that every case of malaria is investigated thoroughly and necessary measures taken to prevent the re-introduction of malaria. It is doubly so in this case, as $P$. ovale is not considered endemic in Sri Lanka and thus determining the parasite origin of importation would be of utmost importance for ongoing surveillance efforts. This patient had traveled widely, visiting malaria endemic areas both within and beyond the shores of the country. During his stay in Liberia 1.5 years prior to his illness, he had been on malaria prophylaxis with mefloquine. Suppressive prophylaxis provided by mefloquine is effective against $P$. falciparum, but will not prevent relapses caused by $P$. ovale [30]. Thus, a $P$. ovale infection acquired while residing in Liberia could have relapsed several years later. Sporadic cases of $P$. ovale malaria have also been reported from various parts of India $[31,32]$. Since transmission of $P$. ovale in India is not widespread, it seems likely that this patient acquired his infection from Liberia where $P$. ovale is known to be endemic $[12,13]$.

This new era emphasizes the global nature of regional malaria elimination. Now more than ever is there an urgent need for next-generation detection methods, not just for the species historically present in the population, but also for introduced or uncommon species. Accurate molecular diagnostic techniques need to be established in Sri Lanka for the screening and diagnosis of all species 
of human malaria infections, especially those that may occur with low parasitemia and likely to be undetected by the routine techniques currently in use. In this case, although the detailed history was suggestive of an imported transmission, confirmation of parasite origin was not possible. Increasing global surveillance and tool development is required to "fingerprint" parasites and identify their origin. The next generation of 'network communities' utilizing genomic advances may offer increased ability to identify 'hotspots' and 'hot-pops', the source and sink of parasites, on a global scale [33].

\section{Abbreviations}

BLAST: Basic Local Alignment Search Tool; bw: Body weight; kg: Kilogram; mg: Milligram; NCBI: National Center for Biotechnology Information; PCR: Polymerase chain reaction; RDT: Rapid diagnostic tests; WHO: World Health Organization

\section{Acknowledgements}

We are thankful to Ms. Lalanthika Peiris of the Regional Office Ambalantota, Anti Malaria Campaign, Ministry of Health, Sri Lanka, for follow-up of the patient. We also gratefully acknowledge Mr. Saman Weerasekera of the Department of Parasitology, University of Ruhuna and Mr. GMG Kapilananda of the Department of Parasitology, University of Colombo, for technical assistance.

\section{Funding}

Not applicable.

\section{Availability of data and materials}

All relevant data and materials are included in the manuscript.

The patient sample sequence has been deposited to GenBank as accession number KY111277.

\section{Authors' contributions}

TCY and MW: Diagnosis and management of patient and editing of manuscript; RFD, KD, SKV and DFW: Molecular diagnosis, designing, writing and editing of manuscript. SG and NDK: Overall coordination, designing, writing and editing of manuscript. All authors read and approved the final manuscript.

\section{Competing interests}

The authors declare that they have no competing interests.

\section{Consent for publication}

Written informed consent for publication of clinical details and images was obtained from the patient.

\section{Ethics approval and consent to participate}

Ethical clearance was provided by the Ethics Review Committee, Faculty of Medicine, University of Colombo, Sri Lanka (EC-08-092) and the Institutional Review Board of Harvard T.H. Chan School of Public Health, USA (10299). Consent for participation was provided by the patient.

\section{Author details \\ ${ }^{1}$ Department of Parasitology, Faculty of Medicine, University of Colombo, 25, Kynsey Road, Colombo 8, Sri Lanka. ²Department of Immunology and Infectious Diseases, Harvard T.H. Chan School of Public Health, Boston, MA, USA. ${ }^{3}$ Infectious Disease Initiative, The Broad Institute of MIT and Harvard, Cambridge, MA, USA. ${ }^{4}$ Department of Parasitology, Faculty of Medicine, University of Ruhuna, Karapitiya, Galle, Sri Lanka. ${ }^{5}$ School of Nursing and Health Science, Simmons College, Boston, MA, USA.}

Received: 22 January 2017 Accepted: 20 April 2017 Published online: 24 April 2017

\section{References}

1. Anti Malaria Campaign, Ministry of Health, Sri Lanka. Available at: http://www. malariacampaign.gov.lk/precentation/Home.aspx (accessed Nov 2, 2016).
2. Dharmawardena P, Premaratne RG, Gunasekera WM, Hewawitarane M, Mendis K, Fernando D. Characterization of imported malaria, the largest threat to sustained malaria elimination from Sri Lanka. Malar J. 2015;14:177.

3. Wickramage K, Premaratne RG, Peiris SL, Mosca D. High attack rate for malaria through irregular migration routes to a country on verge of elimination. Malar J. 2013;12(276):276

4. Galappaththy GN, Fernando SD, Abeyasinghe RR. Imported malaria: a possible threat to the elimination of malaria from Sri Lanka? Trop Med Int Health. 2013;18(6):761-8.

5. Wickremasinghe R, Galappaththy GNL, Fernando WAP, de Monbrison F, Wijesinghe RS, Mendis KN, Picot S, Ringwald P, Wickremasinghe AR. Short report: an indegenous case of Plasmodium ovale infection in Sri Lanka. Am J Trop Med Hyg. 2008;78(2):206-7.

6. WHO: Guidelines for the treatment of malaria, 3rd Edition, World Health Organization; 2015. ISBN 9789241549127.

7. Ta TH, Hisam S, Lanza M, Jiram Al, Ismail N, Rubio JM. First case of a naturally acquired human infection with Plasmodium cynomolgi. Malar J. 2014;13(68):68.

8. Daniels RF, Deme AB, Gomis JF, Dieye B, Durfee K, Thwing JI, Fall FB, Ba M, Ndiop M, Badiane AS, et al. Evidence of non-Plasmodium falciparum malaria infection in Kedougou, Senegal. Malar J. 2017;16(1):9.

9. WHO certifies Sri Lanka malaria-free. http://www.searo.who.int/mediacentre/ releases/2016/1631/en/ (accessed Nov 2, 2016).

10. Karunaweera ND, Galappaththy GN, Wirth DF. On the road to eliminate malaria in Sri Lanka: lessons from history, challenges, gaps in knowledge and research needs. Malar J. 2014;13(59):59.

11. Cohen JM, Smith DL, Cotter C, Ward A, Yamey G, Sabot OJ, Moonen B. Malaria resurgence: a systematic review and assessment of its causes. Malar J. 2012;11:122

12. Lysenko AJ, Beljaev AE. An analysis of the geographical distribution of Plasmodium ovale. Bull World Health Organ. 1969:40(3):383-94.

13. Collins WE, Jeffery GM. Plasmodium ovale: parasite and disease. Clin Microbiol Rev. 2005:18(3):570-81.

14. Win TT, Lin K, Mizuno S, Zhou M, Liu Q, Ferreira MU, Tantular IS, Kojima S, Ishii A, Kawamoto F. Wide distribution of Plasmodium ovale in Myanmar. Trop Med Int Health. 2002;7(3):231-9.

15. Fuehrer HP, Starzengruber P, Swoboda P, Khan WA, Matt J, Ley B, Thriemer K Haque R, Yunus EB, Hossain SM, et al. Indigenous Plasmodium ovale malaria in Bangladesh. Am J Trop Med Hyg. 2010;83(1):75-8.

16. Incardona S, Chy S, Chiv L, Nhem S, Sem R, Hewitt S, Doung S, Mercereau-Puijalon O, Fandeur T. Large sequence heterogeneity of the small subunit ribosomal RNA gene of Plasmodium ovale in cambodia. Am J Trop Med Hyg. 2005;72(6):719-24.

17. Fuehrer HP, Habler VE, Fally MA, Harl J, Starzengruber P, Swoboda P, Bloeschl I, Khan WA, Noedl H. Plasmodium ovale in Bangladesh: genetic diversity and the first known evidence of the sympatric distribution of Plasmodium ovale curtisi and Plasmodium ovale wallikeri in southern Asia. Int J Parasitol. 2012:42(7):693-9.

18. Sutherland CJ, Tanomsing N, Nolder D, Oguike M, Jennison C, Pukrittayakamee S, Dolecek C, Hien TT, do Rosario VE, Arez AP, et al. Two nonrecombining sympatric forms of the human malaria parasite Plasmodium ovale occur globally. J Infect Dis. 2010;201(10):1544-50.

19. Fuehrer HP, Noedl H. Recent advances in detection of Plasmodium ovale: implications of separation into the two species Plasmodium ovale wallikeri and Plasmodium ovale curtisi. J Clin Microbiol. 2014;52(2):387-91.

20. Mueller I, Zimmerman PA, Reeder JC. Plasmodium malariae and Plasmodium ovale-the "bashful" malaria parasites. Trends Parasitol. 2007;23(6):278-83.

21. Strydom KA, Ismail F, Frean J. Plasmodium ovale: a case of not-so-benign tertian malaria. Malar J. 2014;13(85):85

22. Tomar LR, Giri S, Bauddh NK, Jhamb R. Complicated malaria: a rare presentation of Plasmodium ovale. Trop Doct. 2015;45(2):140-2.

23. Trager W, Most H. A long-delayed primary attack of Ovale malaria. Am J Trop Med Hyg. 1963;12:837-9.

24. Rojo-Marcos G, Cuadros-Gonzalez J, Gete-Garcia L, Gomez-Herruz P, Lopez-Rubio M, Esteban-Gutierrez G. Plasmodium ovale infection: description of 16 cases and a review. Enferm Infecc Microbiol Clin. 2011;29(3):204-8.

25. Cao Y, Wang W, Liu Y, Cotter C, Zhou H, Zhu G, Tang J, Tang F, Lu F, Xu S, et al. The increasing importance of Plasmodium ovale and Plasmodium malariae in a malaria elimination setting: an observational study of imported cases in Jiangsu Province, China, 2011-2014. Malar J. 2016;15:459. 
26. Steenkeste N, Rogers WO, Okell L, Jeanne I, Incardona S, Duval L, Chy S, Hewitt S, Chou M, Socheat D, et al. Sub-microscopic malaria cases and mixed malaria infection in a remote area of high malaria endemicity in Rattanakiri province, Cambodia: implication for malaria elimination. Malar J. 2010;9:108.

27. Baltzell KA, Shakely D, Hsiang M, Kemere J, Ali AS, Bjorkman A, Martensson A, Omar R, Elfving K, Msellem M, et al. Prevalence of PCR detectable malaria infection among febrile patients with a negative Plasmodium falciparum specific rapid diagnostic test in Zanzibar. Am J Trop Med Hyg. 2013;88(2):289-91.

28. Amerasinghe FP: A guide to the identification of the Anopheline mosquitoes (Diptera: Culicidae) of Sri Lanka II. Larvae. Cey J Sci (Bio Sci) 1992;22(1):1-13.

29. Kannathasan S, Antonyrajan A, Srikrishnaraj KA, Karunaratne SHPP, Karunaweera ND, Surendran SN. Studies on prevalence of anopheline species and community perception of malaria in Jaffna district, Sri Lanka. J Vector Borne Dis. 2008:45:231-9.

30. Castelli F, Odolini S, Autino B, Foca E, Russo R. Malaria prophylaxis: a comprehensive review. Pharmaceuticals. 2010;3:3212-39.

31. Marathe A, Date V, Shah HN, Tripathi JR. Plasmodium ovale-a case report from Gujarat. J Vector Borne Dis. 2006;43(4):206-8.

32. Singh $R$, Jain V, Singh PP, Bharti PK, Thomas T, Basak S, Singh N. First report of detection and molecular confirmation of Plasmodium ovale from severe malaria cases in central India. Trop Med Int Health. 2013;18(11):1416-20.

33. Cotter C, Sturrock HJ, Hsiang MS, Liu J, Phillips AA, Hwang J, Gueye CS, Fullman N, Gosling RD, Feachem RG. The changing epidemiology of malaria elimination: new strategies for new challenges. Lancet. 2013;382(9895):900-11.

\section{Submit your next manuscript to BioMed Central and we will help you at every step:}

- We accept pre-submission inquiries

- Our selector tool helps you to find the most relevant journal

- We provide round the clock customer support

- Convenient online submission

- Thorough peer review

- Inclusion in PubMed and all major indexing services

- Maximum visibility for your research

Submit your manuscript at www.biomedcentral.com/submit

C) Biomed Central 